${ }^{1}$ DDS, MSc, PhD, Professor of the Graduate Program in Dentistry, Operative Dentistry Area, Universidade Positivo, Curitiba, PR, Brazil.

${ }^{2}$ DDS, MSc, Graduate student of the Graduate Program in Dentistry, Operative Dentistry Area, Universidade Positivo, Curitiba, PR, Brazil.
Corresponding author: Leonardo Fernandes da Cunha Universidade Positivo 5300 Professor Pedro Viriato Parigot de Souza Street - Curitiba, PR ZIP code: 81280-330

E-mail: cunha_leo@me.com; Tel: +55 41 3317-3403; Fax: +55 41 3317-3082

Received: May 27, 2017 Accepted: July 26, 2017

\section{Physical properties of two bis-acryl interim materials: color stability, flexural strength and shear bond strength to flowable composite resin as add-on material}

\author{
Leonardo Fernandes da Cunha ${ }^{1 \star}$, Ana Beatriz Franco \\ Fernandes ${ }^{2}$, Amanda Mahammad Mushashe ${ }^{2}$, \\ Gisele Maria Correr ${ }^{1}$, Carla Castiglia Gonzaga ${ }^{1}$
}

Aims: The objective of this study was to evaluate the mechanical properties of two bis-acryl interim resin materials, such as color stability, flexural strength and shear bond strength to flowable composite resin, simulating clinical situations when this material has to be used for repair as add-on. Two shades of two bis-acryl interim resin materials [Structur 2 SC (shades Bleach and A2); Protemp 4 (shades A1 and A2)] were evaluated. Discs $(5 \times 1 \mathrm{~mm})$ were fabricated and baseline color was determined after $1 \mathrm{~h}$. Ten specimens were immersed at $37^{\circ} \mathrm{C}$ in solutions of distilled water (control) and cola-based soft drink (Coca-Cola). Color measurements were performed with a spectrophotometer using CIELab parameters. Color readings were again measured after 2 hours, 4 hours, 24 hours and 7 days. Flexural strength was determined using the three-point bending test $(10 \times 1 \times 2 \mathrm{~mm})$ on a universal testing machine $(0.5 \mathrm{~mm} / \mathrm{min})(n=10)$. Discs of bis-acryl resin were embedded in acrylic resin, planned and distributed in 2 groups: G1 - Filtek Z350 Flow/Protemp4 and G2 - Grandio SO Flow/Structure $3(n=15)$. Cylinders $(3.5 \times$ $2 \mathrm{~mm}$ ) were made with the flowable composite resins and polymerized for $20 \mathrm{~s}$. The specimens were stored in distilled water at $37^{\circ} \mathrm{C}$ for $24 \mathrm{~h}$ and subjected to shear bond strength test. Data were analyzed using one-way ANOVA and Tukey's test $(a=0.05) . \Delta E$ values were higher for Structur Bleach (3.08) $)^{\mathrm{a}}$ compared with Protemp 4 (shade A1, 2.22) (shade $A 2,2.25)^{b}$. There were no significant differences between Structur Bleach and Structur A2 (2.62) ${ }^{\text {ab }}$. Coca-Cola presented higher $\Delta \mathrm{E}$ values (3.08) a than (2.00) ${ }^{\mathrm{b}}$. Regarding time, 
$\triangle \mathrm{E}$ values increased from $1.84^{\mathrm{a}}$ after $2 \mathrm{~h}$ to $2.31^{\mathrm{b}}$ after $4 \mathrm{~h}$. The higher values were observed after $24 \mathrm{~h}$ and 7 days $\left(2.93^{\mathrm{c}}\right.$ and $3.09^{\mathrm{d}}$, respectively). No significant differences were observed for the flexural strength of Structur $(22.05 \mathrm{MPa})^{\mathrm{a}}$ and Protemp 4 (19.01 MPa). The repairs executed with Structur/Grandio flow $(9.21 \mathrm{MPa})$ a were similar to those performed with Protemp 4/Z350XT flow $(10.71 \mathrm{MPa})^{\text {a }}$. It can be concluded that the two bis-acyl resins evaluated showed similar physical and mechanical properties.

Keywords: mechanical properties, provisional materials, shear strength, flexural strength, color stability.

\section{Introduction}

Bis-acryl interim resin materials have been extensively applied for prosthetic treatments. Properties such as fastness of set process, ease of handling and aesthetic quality of these materials allow its use in several clinical situations during prosthetic rehabilitation, such as temporary restorations and construction of dental mock up for aesthetic and functional evaluations. As interim material, it is essential that they remain stable over the period of rehabilitation. In order to achieve these purposes, they should present good mechanical properties and good color stability ${ }^{1-4}$.

In the case of aesthetic rehabilitations, such as anterior interim restorations, the color stability of bis-acryl interim resin may be considered one of the most important factors for the clinical success. Different composite resins or different luting cements present distinctive degree of the color change ${ }^{5,6}$. Thus, different bis-acryl interim resin materials may also present distinctive color stability. Color changes over time due to the use of beverages with staining potential (e.g., water, wine, and cola-based soft drink) have been previously described to resin-based materials ${ }^{5,6}$. In addition, inherent properties of different bis-acryl materials can interfere in their color stability. Materials with smoother surfaces and less hydrophilicity tend to present less sorption of staining solutions, therefore, present better color stabil$i^{7}{ }^{7}$. In this way, the effect of different solutions with staining potential on bis-acryl interim resin must be evaluated.

In some clinical situations, interim restorations need to stay in function for a longer period than originally planned. Besides color stability, another important aspect in these cases of long-span interim restoration is their flexural strength ${ }^{4}$. Low flexural strength can lead to fractures, resulting in functional and esthetic problems. However, there is a lack of sufficient information about the mechanical properties of bis-acryl interim resin materials ${ }^{4}$.

Additionally, bis-acryl interim resins may need add-on material for repair, modification of form or reduce discrepancies at the margin ${ }^{8}$. According to the manufacturer recommendation and Lee and Lee ${ }^{8}$ (2015), bis-acryl-based interim material has favorable add-on properties when used with a flowable composite resin.

Thus, the aim of this study is to evaluate the mechanical properties of two bis-acryl interim resin materials, such as color stability, flexural strength and shear bond strength 
to flowable composite resin, simulating clinical situations when this material has to be used for repair as add-on. The hypotheses evaluated were: i) there would be differences between the two bis-acryl materials evaluated regarding color stability, flexural strength and shear bond strength to flowable composite resin; and ii) immersion in different staining solution would induce color changes in the two bis-aryl resins.

\section{Material and Methods}

The materials used in this study and their composition are described in Table 1. Optical and mechanical properties of two bis-acryl materials were evaluated by three steps: evaluation of color stability after immersed in different storage solutions, by means of a spectrophotometer; three bending point assay to test flexural strength and shear bond strength between the bis-acryl materials and two flowable composites.

\section{Color Stability}

Two shades of two bis-acryl interim resin materials [Structur 2 SC (shades Bleach and A2) VOCO, Germany; Protemp 4 (shades A1 and A2) 3M ESPE, St. Paul, MN, USA] were evaluated in this study.

All specimens were prepared at the same laboratory with controlled humidity $(55 \pm 5 \%)$, temperature $\left(23 \pm 1^{\circ} \mathrm{C}\right)$ and illumination conditions. Twenty disk specimens ( $5 \mathrm{~mm}$ in diameter and $1 \mathrm{~mm}$ in thickness) were prepared for each shade and material. Each specimen was made by inserting the bis-acryl resin in a Teflon mold ring and pressed between two 1-mm-thick glass slides (separated by Mylar strips) under finger pressure. All samples were prepared according manufacturers' instructions (4 minutes). The samples were subjected to polishing procedures as described by the manufacturers.

The color measurements were performed with a spectrophotometer (EasyShade Advance, Vita Zahnfabrik, Bad Sackingen, Germany) according to the CIELab coordinates, under a standardized white background. Afterwards, ten specimens were immersed at $37^{\circ} \mathrm{C}$ in solutions of distilled water (control) and cola-based soft drink (Coca-Cola). The specimens were then stored in dark canisters containing water or Coca-Cola at $37^{\circ} \mathrm{C}$, and the color parameters were again measured after 2 hours, 4 hours, 24 hours and 7 days. The CIELab coordinates were used to calculate the color difference $(\triangle \mathrm{E})$ between the "before" (baseline) and "after" periods.

Table 1. Compositions of materials used in this study

$\begin{array}{lll}\text { Material Composition } & \end{array}$

Protemp 4 (3M ESPE, USA)

Bis-GMA, Dimethacrylate polymer, zirconia silica, fumed silica, silane

Structur 2 SC (Voco, Germany)

Bis-GMA, BHT, amines, benzoyl peroxide, dimethacrylates, glass particles

Filtek Z350 (3M Espe, USA) BisGMA, BisEMA, UDMA.TEGDMA, sílica, zirconia,clusters, zirconia/sílica aggregated particles

Grandio SO Flow (Voco, Germay)

Bis-GMA, Bis-EMA, TEGDMA, glass ceramic, functionalized $\mathrm{SiO}_{2}$ nano-particles 
Before each color measurement, the disks were ultrasonic cleaned for 60 seconds and then specimens were dried with absorbent paper. The $\Delta \mathrm{E}$ for each experimental time was calculated using the equation:

$$
\Delta \mathrm{E}=\left[(\Delta \mathrm{L})^{2}+(\Delta \mathrm{a})^{2}+(\Delta \mathrm{b})^{2}\right]^{1 / 2}
$$

where $\Delta \mathrm{L}, \Delta \mathrm{a}$ and $\Delta \mathrm{b}$ are the differences in the respective values before and after aging. The results of $\triangle E$ were analyzed by three-way ANOVA with repeated measures (material, solution and time) and Tukey's HSD test ( $a=0.05)$.

\section{Flexural Strength}

Ten specimens were made for each interim restorative material for the evaluation of the flexural strength. A split stainless steel was used to produce the specimens with $10 \times 2 \times 1 \mathrm{~mm}$. Bis-acryl resins were injected into the mold according, as described previously for disks. Excess material was removed, the specimens were polished and then stored in distilled water at $37^{\circ} \mathrm{C}$ for 24 hours. The flexural strength was determined using the three-point bending test on a universal testing machine (EMIC DL 2000, São José dos Pinhais, PR, Brazil) at a crosshead speed $0.5 \mathrm{~mm} / \mathrm{min}$. The flexural strength (S) in MPa was calculated by the following formula:

$$
\mathrm{S}=3 \mathrm{Fl} / 2 \mathrm{bh}^{2}
$$

where $F$ is fracture load $(N)$, I is the span length $(6 \mathrm{~mm}), \mathrm{b}$ and $\mathrm{h}$ are, respectively, the width and height of the specimen $(\mathrm{mm})$. The results of the flexural strength were analyzed by Student's t test $(a=0.05)$.

\section{Shear Bond Strength}

Thirty bis-acryl specimens of $6 \mathrm{~mm}$ of diameter and $2 \mathrm{~mm}$ of thickness were fabricated, as described previously ( $n=15$ for Structur and Protemp4). After polishing, the specimens were embedded in PVC cylinders with acrylic resin (Jet, Artigos Odontológicos Clássico, São Paulo, Brazil). A Teflon matrix (3.5 mm in diameter and $1 \mathrm{~mm}$ in thickness) were placed onto the bis-acryl resin surface and filled with two flowable composite resins (shade A2, Grandio Flow, for Structur samples and Filtek Z350 XT Flow for Protemp samples, 3M ESPE, St. Paul, MN, USA). The specimens were light-cured through for $20 \mathrm{~s}$ with a LED curing unit (Poly Wireless, Kavo, Joinville, $\mathrm{SC}$, Brazil) at $1100 \mathrm{~mW} / \mathrm{cm}^{2}$. Before adding the flowable resins on bis-acryl specimens, no surface treatment was performed. The specimens were then stored in distilled water at $37^{\circ} \mathrm{C}$ for $24 \mathrm{~h}$. After the storage period, the specimens were submitted to shear bond strength test in a universal testing machine at a crosshead speed of $0.5 \mathrm{~mm} / \mathrm{min}$. Data were analyzed using Student's t test $(a=0.05)$.

\section{Results}

\section{Color Stability}

Means and standard deviations for $\triangle E$ values are presented in Table 2. Significant differences were observed for material $(p=0.008822)$, solution $(p=0.000001)$ and time $(p=0.000001)$. All double $(p<0.0001)$ and triple $(p=0.040033)$ interactions were also significant. $\triangle E$ values were higher for Structur Bleach $(\Delta E=3.08 \pm 2,27)^{\text {a }}$ compared with 
Table 2. Means and standard deviations for $\Delta \mathrm{E}$ values.

\begin{tabular}{lccccc}
\hline \multirow{2}{*}{ Material } & Solution & \multicolumn{4}{c}{$\Delta \mathrm{E}$} \\
\cline { 2 - 5 } & & $\mathbf{2 h}$ & $\mathbf{4 h}$ & $\mathbf{2 4} \mathbf{h}$ & $\mathbf{7}$ days \\
\hline \multirow{2}{*}{ Structur Bleach } & Water & $1.18 \pm 0.46^{\text {de }}$ & $0.97 \pm 0.72^{\mathrm{e}}$ & $2.32 \pm 1,26^{\text {bcde }}$ & $1.61 \pm 0.93^{\text {cde }}$ \\
\cline { 2 - 5 } & Coca-Cola & $2.25 \pm 0.53^{\text {bcde }}$ & $3.92 \pm 1.42^{\text {b }}$ & $6.51 \pm 1.66^{\text {a }}$ & $5.91 \pm 1.29^{\text {a }}$ \\
\hline \multirow{2}{*}{ Structur A2 } & Water & $2.60 \pm 1.77^{\text {bcde }}$ & $2.91 \pm 1.80^{\text {bcde }}$ & $1.77 \pm 0.73^{\text {bcde }}$ & $3.15 \pm 1.12^{\text {bcd }}$ \\
\cline { 2 - 5 } & Coca-Cola & $1.70 \pm 0.84^{\text {cde }}$ & $2.21 \pm 0.63^{\text {bcde }}$ & $3.15 \pm 1.56^{\text {bcd }}$ & $3.46 \pm 2.19^{\text {bc }}$ \\
\hline Protemp A1 & Water & $1.34 \pm 0.75^{\text {cde }}$ & $1.65 \pm 0.54^{\text {cde }}$ & $1.75 \pm 0.6^{\text {bcde }}$ & $1.80 \pm 0.4^{\text {bcde }}$ \\
\hline \multirow{2}{*}{ Protemp A2 } & Coca-Cola & $1.99 \pm 1.20^{\text {bcde }}$ & $2.78 \pm 1.0^{\text {bcde }}$ & $3.10 \pm 0.78^{\text {bcde }}$ & $3.41 \pm 0.9^{\text {bc }}$ \\
\hline & Water & $2.04 \pm 0.65^{\text {bcde }}$ & $1.84 \pm 0.79^{\text {bcde }}$ & $2.37 \pm 0.93^{\text {bcde }}$ & $2.77 \pm 0.94^{\text {bcde }}$ \\
\hline
\end{tabular}

*Means follow by different superscript letter are significantly different $(p<0.05)$.

Protemp 4 (shade $A 1, \Delta E=2.23 \pm 1,04)^{b}$ (shade $\left.A 2, \Delta E=2.26 \pm 0.86\right)^{b}$. There were no significant differences between Structur Bleach and Structur $A 2(\Delta E=2.62 \pm 1.48)^{a b}$. It was observed that Coca-Cola presented higher $\triangle \mathrm{E}$ values $(\triangle \mathrm{E}=3.08 \pm 1.85)^{\mathrm{a}}$ when compared to water $(\triangle \mathrm{E}=2.00 \pm 1.09)^{\mathrm{b}}$. When the storage times were considered, the mean $\Delta \mathrm{E}$ values increased from $1.84 \pm 1.03^{\mathrm{a}}$ after 2 hours to $2.32 \pm 1.30^{\mathrm{b}}$ after 4 hours. The higher values were observed after 24 hours and 7 days $\left(\Delta E=2.93 \pm 1.78^{c}\right)$ and $3.10 \pm 1.65^{\text {d }}$, respectively.

\section{Flexural Strength}

Student's t-test showed no significant difference between the flexural strength of Structur and Protemp4 ( $p=0.115)$. The Structur flexural strength $(22.05 \pm 5.71 \mathrm{MPa})$ was similar to the one presented by Protemp $4(19.01 \pm 3.06 \mathrm{MPa})$.

\section{Shear Bond Strength}

There were no statistically significant differences between the materials tested $(p=0.228)$. The repairs executed with Structur/Grandio flow $(9.21 \pm 3.72 \mathrm{MPa})^{\mathrm{a}}$ were similar to those performed with Protemp4/Z350XT flow $(10.71 \pm 2.86 \mathrm{MPa})^{\text {a }}$. All the failures were adhesive.

\section{Discussion}

The hypotheses tested about color stability in the present study were accepted. There were significant differences between the shades evaluated, the immersion solutions used and different periods of time.

The staining of dental materials is the result of both extrinsic and intrinsic factors ${ }^{9}$. Cola-based soft drinks, wine, tea and coffee, for example, are commonly consumed beverages and other studies have demonstrated the discoloration of composite materials upon exposure to these solutions ${ }^{9-11}$. Although the immersion for longer periods of time does not represent a clinical situation, this method provides a better understanding of the staining potencial of several solutions and color stability of materials subjected to immersion. Other studies used this method to verify color stability of materials ${ }^{10-13}$. In the present study, immersion in water and cola-based soft drink caused changes in color of both materials studied, however, the color 
changed was significantly higher for the cola-based drink. The results of this study indicated that the dietary habits of the patient could present a potential discoloration risk to provisional restorations. Also, the water absorbed by the resin matrix can cause filler matrix debonding and hydrolytic degradation of the material ${ }^{14,15}$. However, in the present study, the two bis-acryl materials tested demonstrated no significant differences for color change.

The effect of shades on the color stability of composite resins and luting cements was previously described ${ }^{6,15-18}$. In the present study, the color change for the materials with lighter and less chromatic shades was higher. These results corroborate with those found by Uchida et al. ${ }^{17}$ (1998). These authors, by means of a quantitative analysis of color stability, verified a higher $\Delta E$ for the lighter shades of two composites. This study suggests that this fact may result from two factors: (a) discoloration through environmental breakdown of the polymer leading to release of monomers and the shift of color from the cured resin to that of the monomers and (b) the environmental effect on the retention and/or stability of pigments and other additives in the polymer formulations. The environmental effect on the pigments and other additives need clarification through additional research.

$\triangle E$ values showed a tendency to increase as immersion period increased, suggesting that the color of the material would tend to change over long-term clinical use ${ }^{6,15}$. However, all the values reported color changes with $\triangle E$ values lower than the 3.3 threshold, being clinically acceptable ${ }^{19}$.

The flexural strength of an interim restorative material is considerably tested during mastication. Acceptable flexural strength is crucial to avoid repair procedures that can be time consuming or the fracture of these restorations can lead to functional and aesthetic problems. This factor is especially important in multiple-unit or long-span prosthesis, whose pontics are constantly submitted to flexural tensions during function $^{4}$. In the present study, the materials tested presented similar acceptable flexural strength. Flexural strength test usually follow the ISO 4049 standard that state specimen with $25 \times 2 \times 2 \mathrm{~mm}$. The dimensions used in the present study are different from the ISO, however also observed in prior studies ${ }^{20-22}$. Other dimensions are also used in the literature, such at Vieira et al. ${ }^{22}$ (2012) and Firoozmand and Pagani ${ }^{23}$ (2009).

Distinctive methods can evaluate the bond strength to determine the adhesion between different materials, such as microtensile, microshear or shear bond strength ${ }^{24}$. Besides its irregular distribuition of stress within the surface, shear bond strength tests are easier to perform when compared to microtensile and micro shear assays. Similarly to many studies ${ }^{8,25-28}$, here, the shear bond strength method was used to determine the bond strength between bis-acryl interim resin materials and flowable composite resin, simulating an add-onrepair or modification of form. This method has the advantage to mimic the clinical condition very closely because it results in stress on the interface between the materials ${ }^{8,24-28}$. This study showed no differences between the two materials tested, regarding bond strength. Also, additional treatments have been proposed to improve the bond strength of these materials, such as, applying bonding agent or additional light polymerization ${ }^{8}$. Lee and Lee (2015), verified that the use of those methods increased the shear bond strength of add-on materials to bis-acryl resins when compared to the untreated specimens. 
However, other studies are still necessary to corroborate the clinical use of these strategies, particularly in cases of interim restorations used in oral rehabilitation that remain in function for long periods of time.

This study has a number of limitations, mostly related to the conditions represented. In order to promote a better clinical correlation of the outcomes, more variables should be assessed, such as thermocycling of optical and mechanical properties specimens and immersion in solutions with different $\mathrm{pH}$. In addition, different polishing and finishing protocols can be evaluated to identify the changes in color stability of bis-acryl resins. Thus, future studies must be performed to evaluate the clinical performance of these materials.

Therefore, based on the results of the present study, it can be concluded that the color stability of the bis-acryl resin tests decreased with storage time and storing in cola-based soft drink. There was no difference between materials regarding fleruxal strength and shear bond strength.

\section{References}

1. Haselton DR, Diaz-Arnold AM, Dawson DV. Color stability of interim crown and fixed partial denture resins. J Prosthet Dent. 2005 Jan;93(1):70-5.

2. Stansbury JW, Trujillo-Lemon M, Lu H, Ding X, Lin Y, Ge J. Conversion-dependent shrinkage stress and strain in dental resins and composites. Dent Mater. 2005 Jan; 21(1):56-67.

3. Balkenhol M, Knapp M, Ferger P, Heun U, Wostmann B. Correlation between polymerization shrinkage and marginal fit of temporary crowns. Dent Mater. 2008 Nov; 24(11): 1575-84.

4. Mehrpour H, Farjood E, Giti R, Barfi Ghasrdashti A, Heidari H. Evaluation of the Flexural Strength of Interim Restorative Materials in Fixed Prosthodontics. J Dent (Shiraz). 2016 Sep;17(3):201-6.

5. Spina DR, Grossi JR, Cunali RS, Baratto Filho F, da Cunha LF, Gonzaga CC, et al. Evaluation of Discoloration Removal by Polishing Resin Composites Submitted to Staining in Different Drink Solutions. Int Sch Res Notices. 2015 Aug; 20(1):2015:853975. doi: 10.1155/2015/853975.

6. Pissaia JF, Correr GM, Gonzaga CC, Cunha LF. Influence of shade, curing mode, and aging on the color stability of resin cements. Braz J Oral Sci. 2015 Oct;14(4): 272-5.

7. Berber A, Cakir FY, Baseren M, Gurgan S. Effect of different polishing systems and drinks on the color stability of resin composite. J Contemp Dent Pract. 2013 Jul;14(4): 662-7.

8. Lee J, Lee S. Evaluation of add-on methods for bis-acryl composite resin interim restorations. J Prosthet Dent. 2015 Oct;114(4):594-601. doi: 10.1016/j.prosdent.2015.02.020.

9. Reddy PS, Tejaswi KLS, Shetty S, Annapoorna BM, Pujari SC, Thippeswamy HM. Effects of commonly consumed beverages on surface roughness and color stability of the nano, microhybrid and hybrid composite resins: an in vitro study. J Contemp Dent Pract. 2013 Jul;14(4):718-23.

10. Rutkunas V, Sabaliauskas V, Mizutani H. Effects of different food colorants and polishing techniques on color stability of provisional prosthetic materials. Dent Mater J. 2010 Mar;29(2):167-76.

11. Ferracane JL, Berge HX, Condon JR. In vitro aging of dental composites in water--effect of degree of conversion, filler volume, and filler/matrix coupling. J Biomed Mater Res. 1998 Dec;42(3):465-72.

12. Güler AU, Yilmaz F, Kulunk T, Guler E, Kurt S. Effects of different drinks on stainability of resin composite provisional restorative materials. J Prosthet Dent. 2005 Aug;94(2):118-24.

13. Cakan U, Kara HB. Effect of liquid polishing materials on the stainability of bis-acryl interim restorative material in vitro. J Prosthet Dent. 2015 May;113(5):475-9. doi: 10.1016/j.prosdent.2014.09.020. 
14. Söderholm KJ, Zigan M, Ragan M, Fischlschweiger W, Bergman M. Hydrolytic degradation of dental composites. J Dent Res. 1984 Oct; 63(10):1248-54.

15. Koishi Y, Tanoue N, Atsuta M, Matsumura H. Influence of visible-light exposure on colour stability of current dual-curable luting composites. J Oral Rehabil. 2002 Apr;29(4):387-93.

16. Ruyter IE, Nilner K, Moller B. Color stability of dental composite resin materials for crown and bridge veneers. Dent Mater. 1987 Oct;3(5):246-51.

17. Uchida H, Vaidyanathan J, Viswanadhan T, Vaidyanathan TK. Color stability of dental composites as a function of shade. J Prosthet Dent. 1998 Apr;79(4):372-7.

18. Lee YK, Powers JM. Color and optical properties of resin-based composites for bleached teeth after polymerization and accelerated aging. Am J Dent. 2001 Dec;14(6): 349-54.

19. Kadiyala KK, Badisa MK, Anne G, Anche SC, Chiramana S, Muvva SB, et al. Evaluation of flexural strength of thermocycled interim resin materials used in prosthetic rehabilitation- an in-vitro study. J Clin Diagn Res. 2016 Sep;10(9):ZC91-ZC95.

20. Fonseca RB, Marques AS, Bernades K de O, Carlo HL, Naves LZ. Effect of glass fiber incorporation on flexural properties of experimental composites. Biomed Res Int. 2014;2014:542678. doi:10.1155/2014/542678.

21. Fonseca RB, de Paula MS, Favarão IN, Kasuya AV, de Almeida LN, Mendes GA, et al. Reinforcement of dental methacrylate with glass fiber after heated silane application. Biomed Res Int. 2014;2014:364398. doi: 10.1155/2014/364398.

22. Vieira C, Silva-Sousa YT, Pessarello NM, Rached-Junior FA, Souza-Gabriel AE. Effect of highconcentrated bleaching agents on the bond strength at dentin/resin interface and flexural strength of dentin. Braz Dent J. 2012;23(1):28-35

23. Firoozmand LM, Pagani C. Influence of bleaching treatment on flexural resistance of hybrid materials. Acta Odontol Latinoam. 2009;22(2):75-80.

24. da Cunha LF, Nascimento BM, Baratto SSP, Gonzaga CC, Furuse AY, Mondelli J, et al. Influence of different surface treatments on the shear bond strength of a methacrylate resin composite repaired with silorane-based resin. RSBO. 2013 Jul-Sep;10(3):240-4.

25. Hagge MS1, Lindemuth JS, Jones AG. Shear bond strength of bis-acryl composite provisional material repaired with flowable composite. J Esthet Restor Dent. 2002;14(1):47-52.

26. Chen HL, Lai YL, Chou IC, Hu CJ, Lee SY. Shear bond strength of provisional restoration materials repaired with light-cured resins. Oper Dent. 2008 Sep-Oct;33(5):508-15. doi: 10.2341/07-130.

27. Shim JS, Park YJ, Manaloto A, Shin S, Lee J, Choi Y, Ryu J. Shear bond strength of four different repair materials applied to bis-acryl resin provisional materials measured 10 minutes, one Hour, and two days after bonding. Oper Dent. 2014 Jul-Aug;39(4): E147-53. doi: 10.2341/13-196-L.

28. Shim JS, Lee JY,Choi YJ, Shin SW, Ryu JJ. Effect of light-curing, pressure, oxygen inhibition, and heat on shear bond strength between bis-acryl provisional restoration and bis-acryl repair materials. J Adv Prosthodont. 2015 Feb;7(1):47-50. doi: 10.4047/jap.2015.7.1.47. 